\title{
Evaluation of Metastatic Cutaneous Lesions on Fine Needle Aspiration Cytology: A Five Year Study
}

\author{
Syed Besina Yasin, Naheena Bashir and Subuh Parvez Khan* \\ Department of Pathology, Sher e Kashmir Institute of Medical Sciences, Soura, Srinagar, J \&K India.
}

\section{ABSTRACT}

Background: Cutaneous and subcutaneous metastatic deposits are rare and can be seen in $0.8-5 \%$ cases. This study was done to evaluate the role of Fine Needle Aspiration Cytology(FNAC) in the diagnosis of cutaneous and subcutaneous nodules in patients with known malignancy or as a primary manifestation of an unknown malignancy.

Methods: It was a 5 year retrospective study and the record of patients subjected to FNAC during this period was reviewed.

Results: Out of total number of 13572 patients 58(0.42\%) were diagnosed as cutaneous /subcutaneous metastatic deposits .In 51 cases ,the primary was known and in 7 cases it was an initial manifestation of an unknown primary. There were 39 males and 19 females with age range of 27-82 years .

Conclusion: Commonest site of metastases was chest wall and most common primary was lung. Adenocarcinoma was the commonest diagnosis on morphology. This study emphasizes the efficacy of FNAC on the accurate diagnosis of subcutaneous nodules especially in patients with known malignancy .It also offers clue to the underlying malignancy in occult primary.

\section{Keywords: FNAC, Metastases, Cutaneous}

\section{Introduction}

Cutaneous and subcutaneous metastates from an underlying malignancy is rare. The incidence of cutaneous metastases ranges from $0.8-9 \%[1,2,3,4]$ Typically they are associated with an advanced stage of diaease and a poorer prognosis .[4]Metastatic skin nodules may resemble other primary skin tumours or inflammatory lesions and needs histological or cytological confirmation.

FNAC is a minimally invasive technique for early diagnosis of such cases and thus obviates the need for more invasive biopsies or surgeries. $[1,2,5]$ It offers a clue to underlying malignancy in case of an occult primary[5]

This study was done to evaluate the role of FNAC in the diagnoses of metastatic cutaneous and subcutaneous nodules in patients with known malignancy or as a primary manifestation of an unknown malignancy.

\section{Materials and Methods}

This was a 5 year retrospective study conducted in the pathology department of SKIMS ,Srinagar ,Kashmir which is a tertiary care hospital and a Regional Cancer Centre.The record of all FNACs done from Jan 2011 to Dec 2015 were reviewed .A total of 13572 patients underwent FNAC during this period out of which 58 cases of cutaneous and subcutaneous metastatic deposits were diagnosed.Cases suspected as primary skin tumours were excluded from the study.

FNAC was performed using the conventional techniques. Both dried and alcohol fixed smears were prepared and stained with Giemsa and Pap respectively .Clinicopathologic correlation was done in every case .Slides were reviewed and data analysed.

\section{Results}

Total number of 13572 patients were subjected to FNAC during a five year period (2011-2015). Out of these 58 cases $(0.42 \%)$ were diagnosed as cutaneous /subcutaneous metastatic deposits from a known /unknown primary malignancy.The data was analysed [Table 1,2,3]

The age of patients ranged between 30-82 years in males and 27-70 years in females. The youngest patient was a 27 year female having a metastatic deposit in interscapular area from a primary epitheloid sarcoma left arm. The oldest patient was 82 year male with metastatic mucinous adenocarcinoma from ascending colon, lesion was on anterior abdominal wall.

The most common site of cutaneous metastases was chest wall in 16 cases $(9.28 \%)$ and anterior abdominal wall in 14 cases $(8.12 \%)$ followed by scalp $(3.4 \%)$ and back $(3.4 \%)$. In 48 cases $(82.7 \%)$ there was a solitary metastatic nodule whereas they were multiple in 10 cases(17.2\%). Size of the lesion varied from $0.5-6 \mathrm{~cm}$. 
The most common primary was lung (13 cases $-25.4 \%)$ followed by esophagus (10 cases-19.6\%). There were 51 cases $(87,9 \%)$ with known primary and $7(12.06 \%)$ cases in whom the primary was unknown .On cytomorphology adenocarcinoma[Figure 1] was the commonest diagnoses (22 cases $-37.9 \%$ ) followed by Squamous cell carcinoma(SCC) (19 cases -32.7\%)[Figure 2] which was compatible with the morphology of primary lesion.Some unusual cases were also seen in our study. 3 cases in this series with subcutaneous deposits were known cases of sarcomas (1 epitheloid sarcoma, 1 leiomyosarcoma of soft tissue and 1 rhabdomyosarcoma nose).There was a case of hurthle cell carcinoma thyroid metastasizing to right chest wall .We had 2 cases of Non Hodgkin Lymphoma(NHL) with cutaneous metastates. A 75 year old male presented with a soft jelly like solitary tumor in the chest wall. FNAC revealed features of Anaplastic Large Cell Lymphoma on subsequent examination and investigation .Patient also had generalised nodal involvement .Diagnosis was confirmed on Immunohistochemisrty. There was a case of small cell neurendocrine carcinoma of salivary gland with metastasis to scalp.

Higher incidence was seen in males -39 cases $(67.2 \%)$ than females -9 cases $(37.2 \%)$ ).In 7 cases of unknown primary subsequent detailed work up revealed the primary site as colon and stomach in 3 cases and lung and esophagus in 2 cases of squamous cell carcinoma. 1 case of metastatic neuroendocrine carcinoma had primary in prostate and there was a case of nodal NHL who initially presented as subcutaneous nodule.

Table 1:

\begin{tabular}{|l|c|c|c|}
\hline Site of metastasis & Males & Females & Total (\% age) \\
\hline Chest wall & 12 & 4 & $16(9.28 \%)$ \\
\hline Anterior abdominal wall & 9 & 5 & $14(8.12 \%)$ \\
\hline Scalp & 4 & 2 & $6(3.48 \%)$ \\
\hline Peri-umblical & 1 & 3 & $4(2.32 \%)$ \\
\hline Upper limb & - & 1 & $1(0.58 \%)$ \\
\hline Lower limb & 1 & 1 & $2(1.16 \%)$ \\
\hline Back & 4 & 2 & $6(3.48 \%)$ \\
\hline Scar site & 4 & & $4(2.32 \%$ \\
\hline Groin & 1 & 1 & $2(1.16 \%$ \\
\hline Face & & 1 & $1(0.58 \%)$ \\
\hline Sacral & 1 & & $1(0.58 \%)$ \\
\hline Neck & $\mathbf{3 8 ( 6 5 . 5 \% )}$ & $\mathbf{2 0 ( 3 4 . 4 8 \% )}$ & $1(0.58 \%)$ \\
\hline Total & \multicolumn{2}{|c|}{$\mathbf{5 8 ( 1 0 0 \% )}$} \\
\hline
\end{tabular}

Table 2:

\begin{tabular}{|c|c|c|c|c|c|c|c|}
\hline Primary Tumor & Morphological Diagnosis & Males & Females & Site of Metastasis & Number & Single & Multiple \\
\hline \multirow{3}{*}{ Lung } & SCC -6 & 11 & 2 & chest wall (9) & 13 & 8 & 5 \\
\hline & Small cell carcinoma-3 & & & Abdominal wall (2) & & & \\
\hline & Adenocarcinoma-4 & & & Back(2) & & & \\
\hline Esophagus & SCC & 8 & 2 & & 10 & 5 & 5 \\
\hline Stomach & Adenocarcinoma & 1 & 1 & Abdominal wall & 2 & 2 & \\
\hline Colon & Adenocarcinoma & 1 & & Abdominal wall & 1 & & 1 \\
\hline $\begin{array}{l}\text { GastroEsophageal } \\
\text { junction }\end{array}$ & Adenocarcinoma & 1 & & Para umblical & 1 & 1 & \\
\hline Gall Bladder & Papillary Adenocarcinoma & & 3 & Abdominal wall & 3 & 2 & 1 \\
\hline Ovary & Papillary Adenocarcinoma & & 2 & $\begin{array}{l}\text { Abdominal wall } \\
+ \text { Paraumblical }\end{array}$ & 2 & 2 & \\
\hline \multirow{2}{*}{ Rectum } & \multirow{2}{*}{ Adenocarcinoma } & \multirow{2}{*}{3} & & scar site-1 & 3 & 3 & \\
\hline & & & & chest wall -2 & & & \\
\hline
\end{tabular}




\begin{tabular}{|c|c|c|c|c|c|c|c|}
\hline Primary Tumor & Morphological Diagnosis & Males & Females & Site of Metastasis & Number & Single & Multiple \\
\hline Breast & Ductal Carcinoma & & 2 & Chest wall & 2 & 2 & \\
\hline Prostate & Adenocarcinoma & 1 & & Paraspinal & 1 & 1 & \\
\hline \multirow{2}{*}{ Soft Tissue } & Epitheloid sarcoma & & 1 & Interscapular & 1 & 1 & \\
\hline & Leiomyosarcoma & & 1 & Abdominal wall & 1 & 1 & \\
\hline Nose & Rhabdomyosarcoma & & 1 & Right Cheek & 1 & 1 & \\
\hline Tonsil & $\mathrm{NHL}$ & & 1 & Right Arm & 1 & 1 & \\
\hline Tongue & SCC & 1 & & Abdominal wall & 1 & 1 & \\
\hline Thyroid & Hurthle Cell Carcinoma & & 1 & Right chest & 1 & 1 & \\
\hline Lymph Node & $\mathrm{NHL}$ & 1 & & Abdominal wall & 1 & 1 & \\
\hline \multirow{2}{*}{ Pancreas } & Papillary Adenocarcinoma & 3 & & Scar site -2 & 3 & 3 & \\
\hline & & & & Parietal wall -1 & & & \\
\hline \multirow{3}{*}{ Skin } & SCC & 2 & & Right Thigh & 1 & 1 & \\
\hline & \multirow{2}{*}{ Malignant Melanoma } & 1 & & Back & 1 & 1 & \\
\hline & & & 1 & Groin & 1 & 1 & \\
\hline Salivary Gland & Small cell Neuroendocrine & 1 & & Scalp & 1 & 1 & \\
\hline
\end{tabular}

Table 3:

\begin{tabular}{|c|c|c|c|c|c|}
\hline No. & FNAC diagnosis & Age & Sex & Site & No of Lesions \\
\hline 1 & Small cell Neuro-endocrine Carcinoma & 75 & $\mathrm{M}$ & Sacral & Solitary \\
\hline 2 & Adenocarcinoma & 70 & $\mathrm{M}$ & Parietal wall & Solitary \\
\hline 3 & Non-Hodgkins Lymphoma & 65 & $\mathrm{M}$ & Chest wall & Solitary \\
\hline 4 & Squamous cell carcinoma & 60 & $\mathrm{M}$ & Chest wall & Solitary \\
\hline 5 & Adenocarcinoma(2) & 35,55 & $\mathrm{~F}$ & Anterior Abdominal wall & Solitary \\
\hline 6 & Squamous cell Carcinoma(Poorly & 50 & $\mathrm{M}$ & Anterior Abdominal wall & Solitary \\
\hline
\end{tabular}

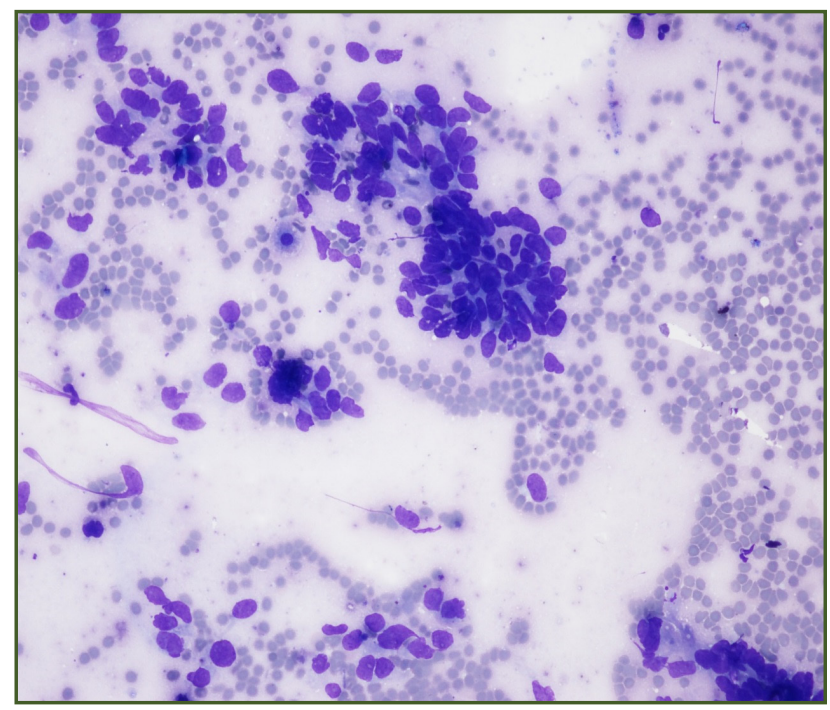

Fig. 1: Photomicrograph showing metastatic deposits of adenocarcinoma.(MGG stain,40X).

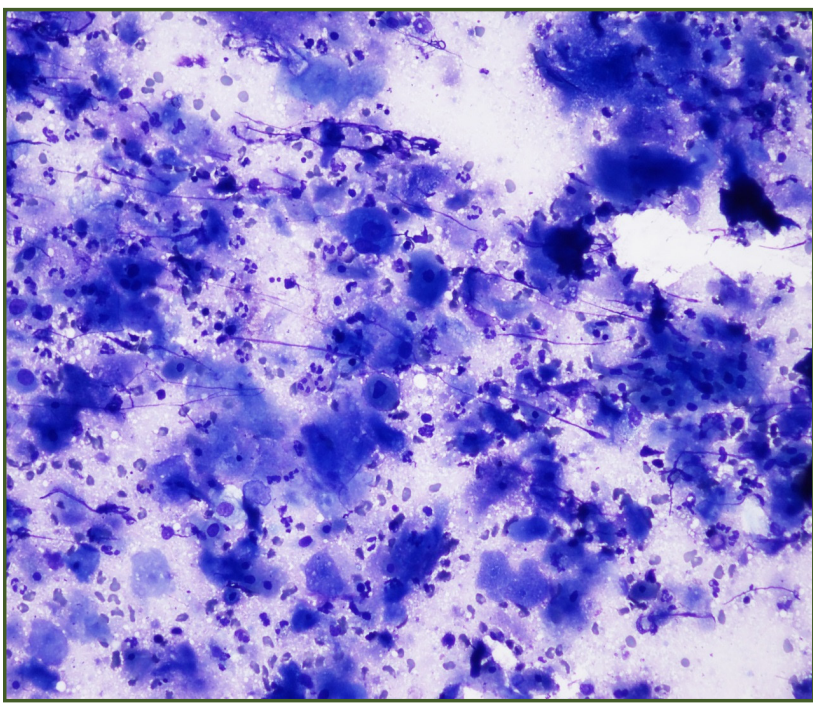

Fig. 2: Photomicrograph showing metastatic deposits of squamous cell carcinoma.(MGG stain ,40X). 


\section{Discussion}

Cutaneous and subcutaneous metastasis is rare.[1,2,3] It can occur due to direct spread from initial tumor or disseminate via vascular or lymphatic route.[6]Cutaneous metastasis are associated with advanced stage of the disease and a poor prognosis.[4]Infrequently it may be the first sign of malignancy $[4,7]$ Clinically cutaneous metastasis manifests as nodules, ulceration, cellulitis like lesions or fibrotic processes. Lesions are solitary or multiple and mostly symptom free.[1,4,5]Histologically, they can be classified as adenocarcinoma, squamous cell carcinoma, undifferentiated carcinoma and other miscellaneous types. [6]Skin metastases usually occurs close to the site of primary tumour -chest in lung carcinoma ,abdominal wall in GI malignancy and lower back in Renal cell carcinomas.

Chest and abdomen is the commonest site of cutaneous metastases reported in the literature followed by head and neck.[1]The most common malignancies to metastasize to skin are lung followed by GI , melanoma , RCC and carcinoma of oral cavity in males. Breast followed by colon ,melanoma ,lung, ovary and sarcoma are the common primary sites in females.[1,4]Adenocarcinoma from various organs is the commonest to metastasize to skin.[1,5]Age ranges between 2-76 years. [1,8]

Differential diagnoses includes primary adnexal tumors and primary squamous cell carcinoma of skin .Metastases is usually located in deeper dermis and subcutaneous tissue and overlying skin is free.[5] Cutaneous metastases also present as first sign of malignancy usually in cancers of lung ,kidney and ovary.[9]Sometimes ,primary sites have not been located even after autopsies.[10,11]

Incidence of cutaneous metastases was $0.42 \%$ in our study. Age ranged between 27-82 years in our patients. Most common site of metastases was chest wall and mostly they were solitary. Lung was the commonest primary in males and gall bladder in females.

Metastatic cutaneous lesions are more often found in women with breast cancer, than with other visceral malignancy with an incidence of upto $20 \%$. However in our series gall bladder malignancy was the commonest primary. There was an unusual case of Hurthle cell carcinoma of the thyroid with cutaneous metastases to the right chest wall. Cutaneous metastases of thyroid carcinoma are infrequent $[12,13,14]$ and FNA is an important method for rapid diagnosis of such lesions [12].There have been fewer than 30 case reports of cutaneous metastases of thyroid carcinoma in the literature with majority to head and neck.[12]

Cutaneous malignancies are less commonly in malignancies such as leukemia and lymphoma 3 cases of secondary NHL skin were seen in our study. Metastases of various types of sarcomas accounts for only $2-3 \%$ of all metastases. Skin lesions ,metastases of sarcoma occurs by hematogenous spread, so cutaneous metastases is an unusual finding.[15] 3 cases of soft tissue sarcomas that had metastases to skin ans subcutaneous tissue were identified in 3 females .The histological types were epitheloid sarcoma, leiomyosarcoma and rhabdomyosarcoma. Metastases occured to interscapular area and abdominal wall .The diagnosis was established by FNAC.2 cases of metastaic neuroendocrine carcinoma were seen in our series .One patient had primary in salivary gland and the other presented with metastases in sacral area.Patient on follow up was found to have neuroendocrine carcinoma prostrate .Cutaneous metastases from neuroendocrine carcinoma of visceral organ has already been reported. When a neuroendocrine carcinoma is found in the skin, it is importantto distinguish Merkel cell carcinoma from cutaneous metastases of visceral origin.Positive staining for CK20 is strongly diagnostic.[17] The diagnosis was confirmed by a complete IHC study of both primary and secondary lesions. Cutaneous metastases of an extracutaneous NHL seems to be poor prognostic factor.[18]

\section{Conclusion}

To conclude FNAC can diagnose a variety of tumours in the skin and support the diagnosis of a metastases in a case known primary and offer a clue to underlying malignancy in case of an occult primary .It is a minimally invasive rapid ,accurate and cost effective tool which helps in the prompt diagnosis of such cases .[19]All cases were correctly diagnosed in our study. Our study supports the utility of this technique in the evaluation of metastatic skin lesions and confirms its high degree of accuracy .

\section{References}

1. Karki S, Pathak R, Manandhar U, Koirala S. Metastatic cutaneous and subcutaneous lesions: Analysis of cases diagnosed on fine needle aspiration cytology. Journal of Pathology of Nepal 2011;1:37-40.

2. Geramizadeh B, Marzban S, Karamifar N et al. Diagnosis of Subcutaneous Metastatic Deposits by Fine Needle Aspiration. J Cytol Histol 2012; 3:151.

3. Nava G, Greer K, Patterson J, Lin KY. Metastatic cutaneous breast carcinoma: A case report and review of the literature. The Canadian Journal of Plastic Surgery 2009;17(1):25-27.

4. Erdemir AT, Atılganoglu U, Onsun N, Somay A. cutaneous metastases from gastric adenocarcinoma. indian journal of dermatology 2011;56(2):236-237.

5. Sharma, S., Kotru, M., Yadav, A., Chugh, M., Chawla, A. and Makhija, M. (2009), Role of fine-needle aspiration cytology in evaluation of cutaneous metastases. Diagn. Cytopathol., 37: 876-880.

e-ISSN: 2349-6991; p-ISSN: 2455-0396 
6. Fyrmpas G, Barbetakis N, Efstathiou A, Konstantinidis I, Tsilikas C. Cutaneous metastasis to the face from colon adenocarcinoma. Case report. Int Semin Surg Oncol 2006;3:2

7. Molina Garrido MJ, Mora Rufete A, Guillen Ponce C, Macia Escalante S, Carrato Mena A. Skin metastases as first manifestation of lung cancer. Clin Transl Oncol. 2006;8:616-617.

8. Bansal R, Patel T, Sarin J, Parikh B, Ohri A, Trivedi P. Cutaneous and subcutaneous metastasis from internal malignancy. An analysis of cases diagnosed by fine needle aspiration. Diagn Cytopathol 2011;39(12) 882-7

9. Schwartz RA. Cutaneous metastatic disease. J Am Acad Dermatol 1995;33:161-82

10. Didolkar MS, Fanous N, Elias EG, Moore RH. Metastatic Carcinomas from Occult Primary Tumors: A Study of 254 Patients. Annals of Surgery 1977;186(5):625-630.

11. Osteen RT, Kopf G, Wilson RE. In pursuit of the unknown primary. Am J Surg. 1978 Apr;135(4):494-497.

12. Rahman G A, Abdulkadir A Y, Olatoke S A, Yusuf I F, Braimoh K T. Unusual cutaneous metastatic follicular thyroid carcinoma. J Surg Tech Case Report 2010;2:35-8
13. Agarwal S, Rao S, Arya A, Gupta K, Arora R, Dhawan I. Follicular thyroid carcinoma with metastasis to skin diagnosed by fine needle aspiration cytology. Indian J Pathol Microbiol 2008;51:430-1

14. Caron $\mathrm{Ph}$, Moreau-Cabarrot A, Gorguet B \& Bazex J. Cutaneous metastasis from follicular carcinoma of the thyroid gland. Thyroid 1993;3:235-237.

15. Corcoran S, Hogan AM, Nemeth T, et al. Isolated cutaneous metastasis of uterine leiomyosarcoma: case report and review of literature. Diagnostic Pathology 2012;7:85.

16. Rao UM, Hanan AH, Karakousis CP. et al. Distant skin and soft tissue metastases from sarcomas. J Surg Oncol. 1998;69:94-98.

17. Fluehler C, Quaranta L, di Meo N, Ulessi B, Trevisan G. Cutaneous Metastasis of Neuroendocrine Carcinoma. Indian Journal of Dermatology 2013;58(3):247.

18. Reich A, Wróbel G, Kazanowska B et al: Skin involvement in highly malignant non-Hodgkin lymphomas of childhood and adolescence. Acta Dermatovenerol Alp Panonica Adriat 2006; 15(4):158-68.

19. Rodrigues LK, Leong SP, Ljung BM, et al.Fine needle aspiration in the diagnosis of metastatic melanoma. J Am Acad Dermatol. 2000;42:735-740.

*Corresponding author:

Dr. Subuh Parvez Khan, Department of Pathology, Sher e Kashmir Institute of Medical Sciences, Soura, Srinagar, J\&K, India.190011

Phone: +919469343742

E-mail: khansubuh@gmail.com 